\title{
Eribulin Inhibits Osteosarcoma in a Clinically-accurate Bone-tumor-insertion PDOX Mouse Model
}

\author{
NATHANIEL F. WU ${ }^{1,2}$, JUN YAMAMOTO ${ }^{1,3}$, YUSUKE AOKI ${ }^{1,3}$, \\ MICHAEL BOUVET $^{3}$ and ROBERT M. HOFFMAN ${ }^{1,3}$ \\ ${ }^{1}$ AntiCancer Inc, San Diego, CA, U.S.A.; \\ ${ }^{2}$ Department of Molecular and Cellular Biology, Harvard University, Cambridge, MA, U.S.A.; \\ ${ }^{3}$ Department of Surgery, University of California, San Diego, CA, U.S.A.
}

\begin{abstract}
Background/Aim: Osteosarcoma is a rare type of bone cancer that affects mostly children and adolescents. Firstline chemotherapy for osteosarcoma has not been improved for many decades. Eribulin has been used to treat breast cancer and liposarcoma in the clinic. Materials and Methods: A patient-derived orthotopic xenograft (PDOX) mouse model of osteosarcoma was established by tumor insertion within the tibia. This model more closely mimics osteosarcoma in clinical settings and was used to test the efficacy of eribulin. Tibiainsertion osteosarcoma PDOX mouse models were randomized into two groups: a control group $(n=4)$ and an eribulintreatment group $(n=5)$. Mice were treated for fourteen days, four weeks after initial implantation. Tumor size and body weight were measured, and tumor histology was examined. Results: Significant tumor growth inhibition $(p=0.044)$ was observed in mice treated with eribulin compared to the control group. Histology demonstrated necrosis in the eribulin-treated tumors. There was no body-weight loss in the treated mice. Conclusion: Eribulin may be a clinically-effective, off-label chemotherapy for recalcitrant osteosarcoma that has failed first- and second-line therapy.
\end{abstract}

Osteosarcoma is a rare bone cancer affecting mostly children and adolescents; there are only 1,000 new cases per year in the United States (1). Surgery, radiation, and a combination of neoadjuvant and adjuvant chemotherapy are first-line treatment for osteosarcoma $(2,3)$. The current first-line

This article is freely accessible online.

Correspondence to: Robert M. Hoffman, Ph.D., AntiCancer Inc, 7917 Ostrow St, San Diego, CA, 92111, U.S.A. Tel: +1 8586542555, Fax: +1 8582684175, e-mail: all@anticancer.com

Key Words: Osteosarcoma, eribulin, PDOX, patient-derived orthotopic xenograft, tibia-insertion implantation, efficacy. chemotherapy for osteosarcoma is a combination of highdose methotrexate, doxorubicin, and cisplatinum (4). Osteosarcoma patients often develop resistance to these drugs, which leads to metastases and fatality (5). Novel, more-effective treatment for osteosarcoma has been difficult to develop. Many previous animal studies testing new therapies for osteosarcoma used subcutaneous-implantation mouse models, which are poor surrogate models of cancer in patients and may not reflect the effectiveness of treatments as accurately as orthotopic-implantation models (6-9).

Our laboratory developed the patient-derived orthotopic xenograft (PDOX) model for many cancer types, including osteosarcoma $(5,10)$. Recently, we developed an improved osteosarcoma PDOX model in which the tumor is inserted into a hole made in the tibia of nude mice in order for the patient osteosarcoma to grow within the bone, as it does clinically (11). Eribulin is a third-line FDA-approved therapy for metastatic breast-cancer patients who were previously treated with an anthracycline and a taxane (12). Eribulin has also been approved for the treatment of metastatic liposarcoma patients who have progressed after anthracycline treatment (12). A Phase II study of eribulin conducted in recurrent or refractory osteosarcoma patients showed no objective responses (4). The present study uses an orthotopic, more-clinically-accurate osteosarcoma mouse model to test eribulin as a potential effective off-label chemotherapy for treating patients with osteosarcoma, who have failed first-line chemotherapy (11).

\section{Materials and Methods}

Mice. The present study was conducted on athymic (nu/nu) nude mice (AntiCancer, Inc., San Diego, CA, USA) and followed an AntiCancer, Inc. Institutional Animal Care and Use Committee (IACUC) protocol specifically approved for this study. The present study followed the principles and procedures outlined in the National Institutes of Health Guide for the Care and Use of Animals under Assurance Number A3873-1. All animal procedures have been previously described (13-20). 

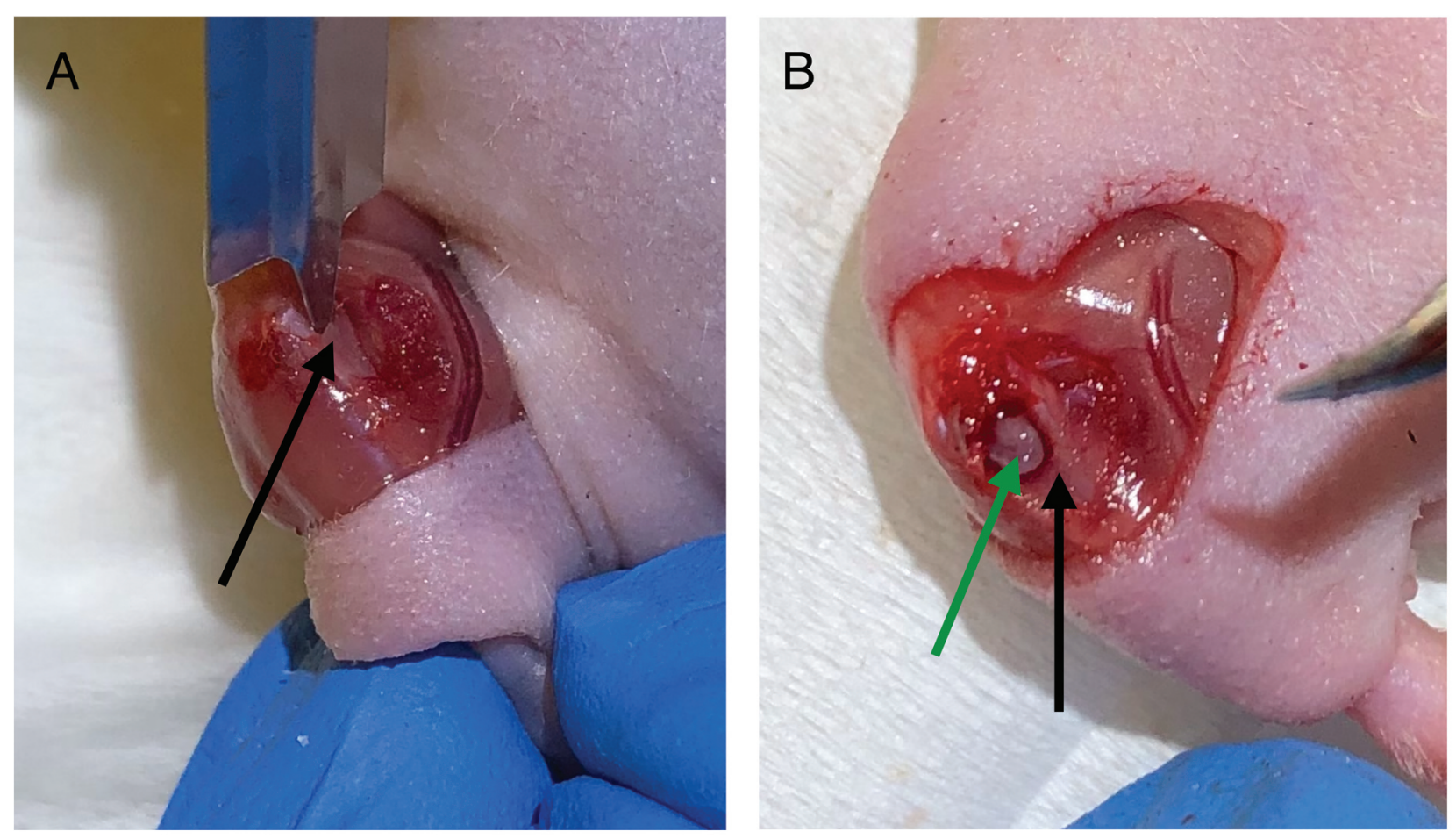

Figure 1. Establishment of a tibia-insertion osteosarcoma PDOX model. The black arrows indicate the tibia bone. (A) Hole made in the tibia by rotating a blade. (B) A one- $\mathrm{mm}^{3}$ tumor fragment was implanted into the hole in the tibia, using a fine tweezer. The green arrow indicates the tumor fragment inserted in the hole created in the tibia.

Patient-derived tumor. The osteosarcoma was obtained previously from a 14-year-old boy with pelvic osteosarcoma following a UCLA Institutional Review Board-approved protocol (IRB\#10-001857) with written informed consent obtained from the patient and his parents. The patient was not administered chemotherapy or radiotherapy before the fresh biopsy sample was taken (20).

Establishment of an orthotopic osteosarcoma tibia-implantation PDOX model. Nude mice with subcutaneously-implanted tumors larger than $10 \mathrm{~mm}$ in diameter were anesthetized with a ketamine mixture and tumor tissue was harvested and divided into $1 \mathrm{~mm}^{3}$ fragments (11). In nude mice, after a skin incision was made and the tibia was exposed, a blade was inserted into the tibia bone and rotated to create a hole 1-mm in diameter (Figure 1A) (11). The tumor fragment was placed inside the hole (Figure 1B). The wound was closed with a 5-0 PDS-II suture.

Treatment scheme. The osteosarcoma PDOX models were divided into two groups randomly, four mice in the control group and five mice in the treatment group. After four weeks, tumor size was measured. The following treatment scheme was performed for two weeks: control group, no treatment; treatment group, eribulin 0.25 $\mathrm{mg} / \mathrm{kg}$ by intraperitoneal injection, once a week (Figure 2). Mice were weighed and tumor size was measured with calipers at one and two weeks after the start of treatment. Tumor volume was calculated as previously described (7). All mice were sacrificed 6 weeks after implantation, as previously described (13-21).
Hematoxylin and eosin staining. Fixation, paraffin sectioning, and staining were performed, as previously described (14). Hematoxylin and eosin (H\&E) staining was performed according to standard protocols (19).

Statistical analysis. All statistical analyses were performed with JMP Pro ver.15.0.0 (SAS Institute, Cary, NC, USA). The Student's $t$-test was used to compare two groups. $p$-values were two-sided, and a $p$ value of $\leq 0.05$ is regarded as statistically significant.

\section{Results}

Efficacy of eribulin on the clinically-relevant osteosarcoma PDOX model. The treatment schema is illustrated in Figure 2. Eribulin inhibited tumor growth of the osteosarcoma PDOX model: At day 14, the mean relative tumor volume (tumor volume value at day 14 divided by tumor volume at day 0 ) in the control mice was $8.9 \mathrm{~mm}^{3}$ and in the eribulintreated mice, relative tumor volume was $5.4 \mathrm{~mm}^{3}(p=0.044)$ (Figure 3). Representative photos of the tumor-bearing mice clearly show eribulin inhibited osteosarcoma growth (Figure 4). There was no significant difference between the relative body weight (calculated by dividing the body weight of mice at day 14 by the body weight at day 0 ) of mice in the control group compared to that in the treatment group (Figure 5). 


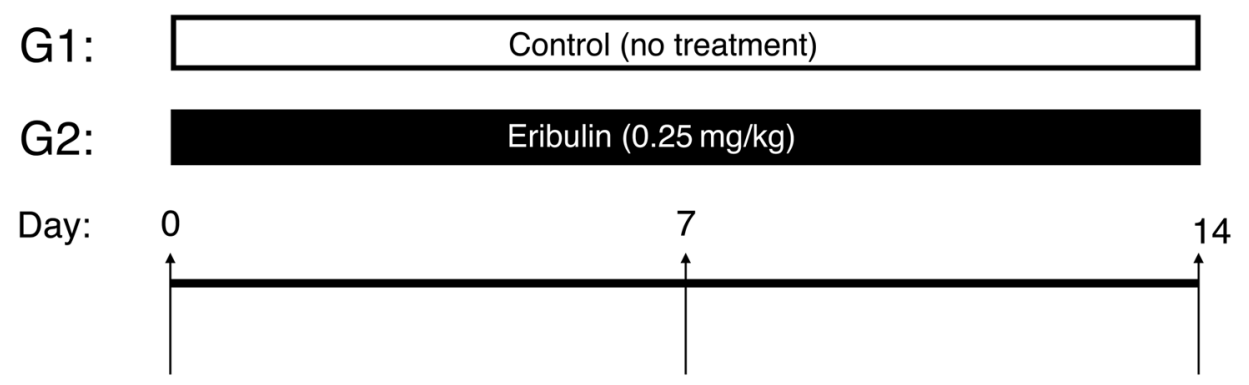

Sacrifice

Figure 2. Schematic of treatment plan. Tumor and body weight measurement: Days 0, 7, 14. Eribulin administered: Days 0 \& 7.

Histology of the treated and control osteosarcoma PDOX model. H\&E staining showed that tumors from the control group comprised viable, highly-dense cancer cells with pleomorphic spindle-shaped cells (Figure 6A). H\&E staining showed that tumors from the treatment group exhibited decreased pleomorphic spindle-shaped cell density, characteristic of necrosis (Figure 6B).

\section{Discussion}

Until recently, most mouse models of osteosarcoma have utilized subcutaneous transplants of tumors, which ignores the fact that osteosarcoma grows in the bones of patients. Our laboratory developed the first-generation orthotopic model of patient osteosarcoma by implanting the tumor into the internal condyle of the femur (21). Although the first-generation PDOX model was a qualitative improvement over the subcutaneous models, the osteosarcoma was growing on the bone rather than in the bone, as it does in patients (21). Recently, we developed a second-generation osteosarcoma PDOX model with a $1 \mathrm{~mm}$ hole made in the mouse tibia, in which the patient osteosarcoma tissue was implanted (11). Thus, in the second-generation osteosarcoma PDOX model the tumor grows within the bone. A bone-insertion model of a bone tumor is far more clinically relevant than subcutaneous models where the tumor is in a heterotopic microenvironment (22).

A recent review has emphasized the importance of patientderived cancer models for rare cancers but claims the paucity of patient-derived mouse models, especially of sarcomas (23). The review fails to cite any of the more than sixty papers on PDOX models of all major types of sarcoma $(5,13-21,24)$.

In a previous study, using the first-generation osteosarcoma PDOX model established from a lung-metastatic osteosarcoma, eribulin was also found to be effective (21). The present study of an osteosarcoma derived from the pelvis, with a more clinically-relevant model, as well as the previous study of an osteosarcoma derived from a lung metastasis, indicate the

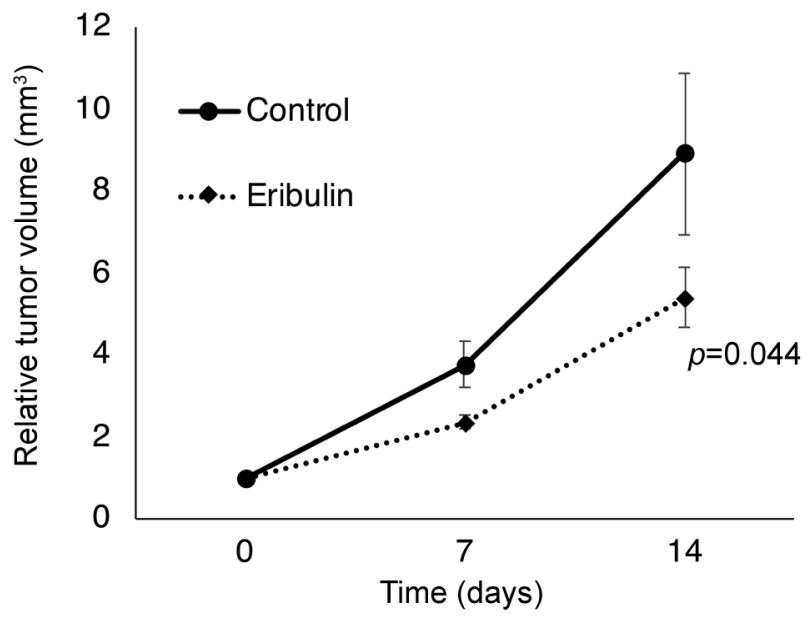

Figure 3. Relative tumor volume (tumor volume at day 7 or 14, divided by tumor volume at day 0$) . N=4$ mice for control group; $N=5$ mice for treatment group. $p<0.05$. Bar: mean \pm SEM.

clinical potential of eribulin for refractory osteosarcoma that has failed first-line or higher lines of chemotherapy. If a patient's osteosarcoma PDOX model shows sensitivity to eribulin, the present and previous results suggest its off-label use for the patient may be considered.

\section{Conflicts of Interest}

AntiCancer uses PDOX models for contract research. N.W., J.Y., Y.A., and RMH are or were unsalaried associates of AntiCancer Inc. The Authors declare that there are no potential conflicts of interest regarding this study.

\section{Authors' Contributions}

N.W., J.Y., and R.M.H designed and performed experiments and wrote the article; J.Y. and Y.A. gave technical support and conceptual advice. N.W., M.B., and R.M.H wrote, reviewed, and/or revised the manuscript. 

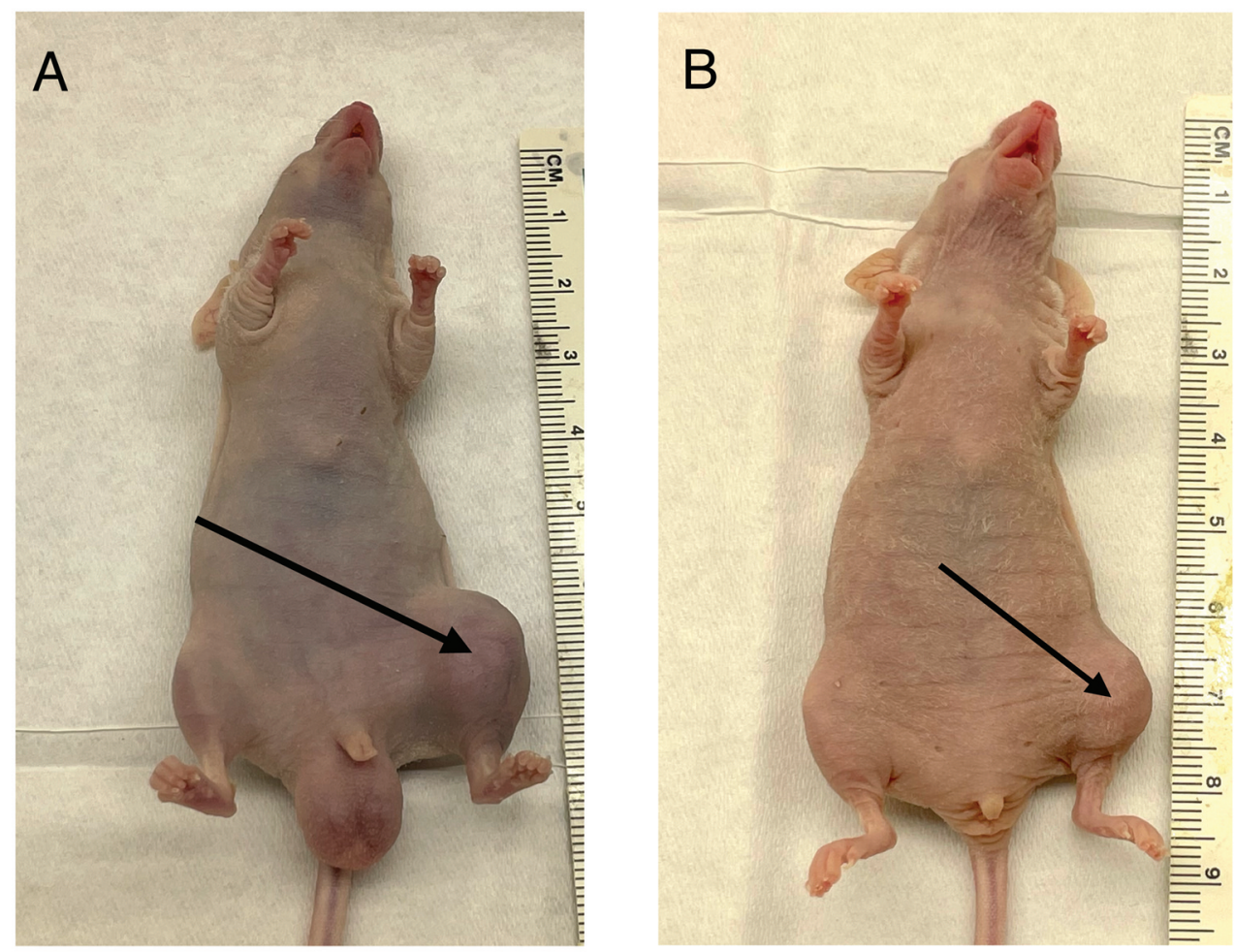

Figure 4. Osteosarcoma orthotopic tibia-insertion PDOX mouse models. Black arrows indicate location of tumors. (A) mouse from untreated control group, day 14. (B) mouse from treatment group, day 14.

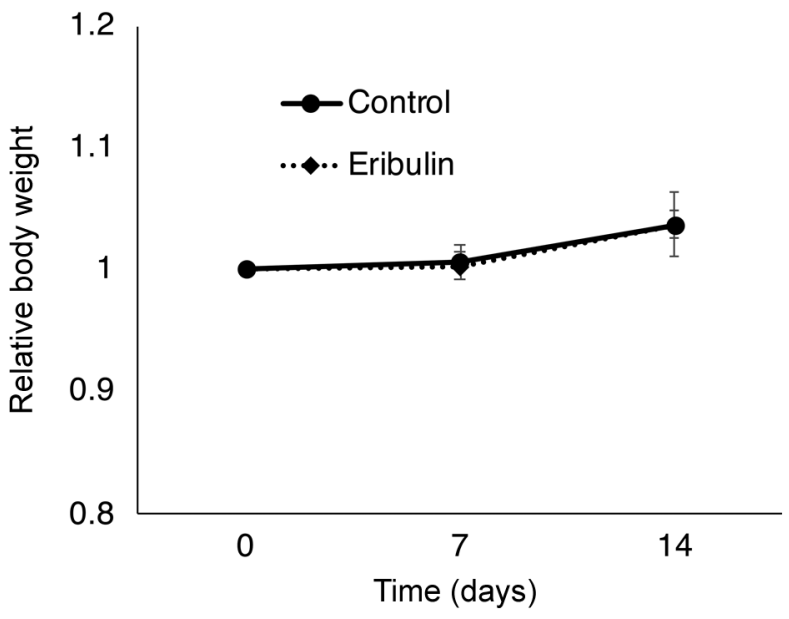

Figure 5. Relative body weight. $N=4$ mice for control group; $N=5$ mice for treatment group. $p>0.05$. Bar: mean \pm SEM.

\section{Acknowledgements}

This paper is dedicated to the memory of A. R. Moossa, M.D., Sun Lee, M.D., Professor Li Jiaxi and Masaki Kitajima, M.D.

\section{Funding}

The present study was funded in part by Robert M. Hoffman Foundation for Cancer Research, which had no role in the design, execution, interpretation, or writing of the study.

\section{References}

1 Howlader N, Noone AM, Krapcho M, Miller D, Brest A, Yu M, Ruhl J, Tatalovich Z, Mariotto A, Lewis DR, Chen HS, Feuer EJ and Cronin KA (eds.): Seer cancer statistics review, 1975-2017. National Cancer Institute. Bethesda, MD, USA. Available at: https://seer.cancer.gov/csr/1975_2017/ [Last accessed on March $8,2021]$

2 Durfee RA, Mohammed M and Luu HH: Review of osteosarcoma and current management. Rheumatol Ther 3(2): 221-243, 2016. PMID: 27761754. DOI: 10.1007/s40744-016-0046-y

3 Harrison DJ, Geller DS, Gill JD, Lewis VO and Gorlick R: Current and future therapeutic approaches for osteosarcoma. Expert Rev Anticancer Ther 18(1): 39-50, 2018. PMID: 29210294. DOI: $10.1080 / 14737140.2018 .1413939$

4 Isakoff MS, Bielack SS, Meltzer $\mathrm{P}$ and Gorlick R: Osteosarcoma: Current treatment and a collaborative pathway to success. J Clin Oncol 33(27): 3029-3035, 2015. PMID: 26304877. DOI: $10.1200 / J C O .2014 .59 .4895$ 

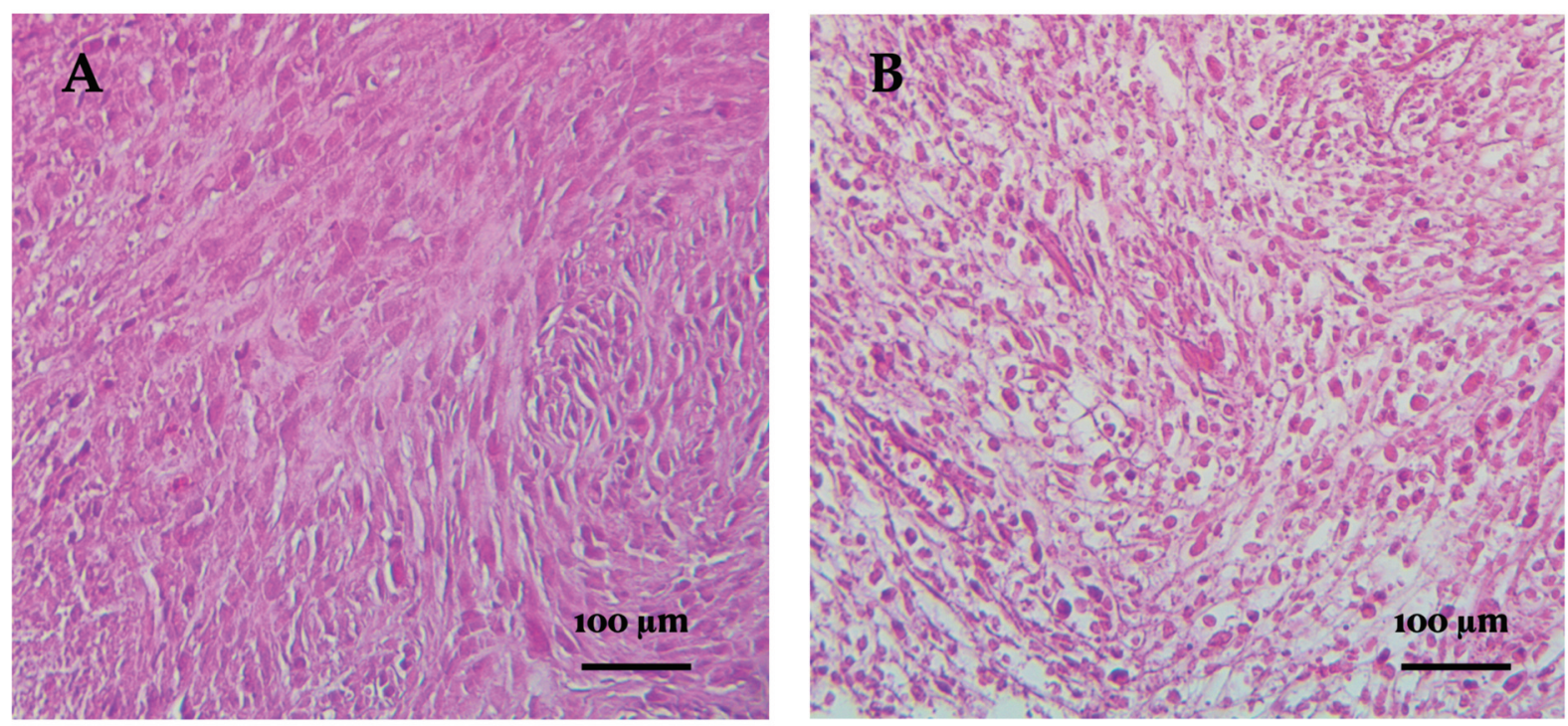

Figure 6. Tumor histology in the osteosarcoma PDOX model. Scale bars: $100 \mu$ m. (A) Tumor sample from the untreated control group. (B) Tumor sample from the treatment group. $100 \times$ Magnification, $H \& E$ staining.

5 Igarashi K, Kawaguchi K, Murakami T, Miyake K, Kiyuna T, Miyake M, Hiroshima Y, Higuchi T, Oshiro H, Nelson SD, Dry SM, Li Y, Yamamoto N, Hayashi K, Kimura H, Miwa S, Singh SR, Tsuchiya H and Hoffman RM: Patient-derived orthotopic xenograft models of sarcoma. Cancer Lett 469: 332-339, 2020. PMID: 31639427. DOI: 10.1016/j.canlet.2019.10.028

6 Nanni P, Landuzzi L, Manara MC, Righi A, Nicoletti G, Cristalli C, Pasello M, Parra A, Carrabotta M, Ferracin M, Palladini A, Ianzano ML, Giusti V, Ruzzi F, Magnani M, Donati DM, Picci P, Lollini PL and Scotlandi K: Bone sarcoma patient-derived xenografts are faithful and stable preclinical models for molecular and therapeutic investigations. Sci Rep 9(1): 12174, 2019. PMID: 31434953. DOI: 10.1038/s41598019-48634-y

7 Gill J, Zhang W, Zhang Z, Roth M, Harrison DJ, Rowshan S, Erickson S, Gatto G, Kurmasheva R, Houghton P, Teicher B, Smith MA, Kolb EA and Gorlick R: Dose-response effect of eribulin in preclinical models of osteosarcoma by the pediatric preclinical testing consortium. Pediatr Blood Cancer 67(10): e28606, 2020. PMID: 32706456. DOI: 10.1002/pbc.28606

8 Smeester BA, Slipek NJ, Pomeroy EJ, Laoharawee K, Osum SH, Larsson AT, Williams KB, Stratton N, Yamamoto K, Peterson JJ, Rathe SK, Mills LJ, Hudson WA, Crosby MR, Wang M, Rahrmann EP, Moriarity BS and Largaespada DA: PLX3397 treatment inhibits constitutive CSF1R-induced oncogenic ERK signaling, reduces tumor growth, and metastatic burden in osteosarcoma. Bone 136: 115353, 2020. PMID: 32251854. DOI: $10.1016 /$ j.bone. 2020.115353

9 Tran Chau V, Liu W, Gerbé de Thoré M, Meziani L, Mondini M, O'Connor MJ, Deutsch E and Clémenson C: Differential therapeutic effects of PARP and ATR inhibition combined with radiotherapy in the treatment of subcutaneous versus orthotopic lung tumour models. Br J Cancer 123(5): 762-771, 2020. PMID: 32546832. DOI: 10.1038/s41416-020-0931-6
10 Hoffman RM: Patient-derived orthotopic xenografts: Better mimic of metastasis than subcutaneous xenografts. Nat Rev Cancer 15(8): 451-452, 2015. PMID: 26422835. DOI: 10.1038/nrc3972

$11 \mathrm{Wu}$ NF, Yamamoto J, Bouvet M and Hoffman RM: A novel procedure for orthotopic tibia implantation for establishment of a more clinical osteosarcoma PDOX mouse model. In Vivo 35(1): 105-109, 2021. PMID: 33402455. DOI: 10.21873/invivo. 12237

12 Seetharam M, Kolla KR and Chawla SP: Eribulin therapy for the treatment of patients with advanced soft tissue sarcoma. Future Oncol 14(16): 1531-1545, 2018. PMID: 29411654. DOI: 10.2217/fon-2017-0461

13 Higuchi T, Oshiro H, Miyake K, Sugisawa N, Han Q, Tan Y, Park J, Zhang Z, Razmjooei S, Yamamoto N, Hayashi K, Kimura H, Miwa S, Igarashi K, Bouvet M, Chawla SP, Singh SR, Tsuchiya $\mathrm{H}$ and Hoffman RM: Oral recombinant methioninase, combined with oral caffeine and injected cisplatinum, overcome cisplatinum-resistance and regresses patient-derived orthotopic xenograft model of osteosarcoma. Anticancer Res 39(9): 4653-4657, 2019. PMID: 31519563. DOI: 10.21873/anticanres.13646

14 Higuchi T, Sugisawa N, Miyake K, Oshiro H, Yamamoto N, Hayashi K, Kimura H, Miwa S, Igarashi K, Bouvet M, Singh SR, Tsuchiya $\mathrm{H}$ and Hoffman RM: The combination of olaratumab with doxorubicin and cisplatinum regresses a chemotherapyresistant osteosarcoma in a patient-derived orthotopic xenograft mouse model. Transl Oncol 12(9): 1257-1263, 2019. PMID: 31299622. DOI: 10.1016/j.tranon.2019.06.002

15 Higuchi T, Sugisawa N, Miyake K, Oshiro H, Yamamoto N, Hayashi K, Kimura H, Miwa S, Igarashi K, Chawla SP, Bouvet M, Singh SR, Tsuchiya H and Hoffman RM: Sorafenib and palbociclib combination regresses a cisplatinum-resistant osteosarcoma in a PDOX mouse model. Anticancer Res 39(8): 4079-4084, 2019. PMID: 31366491. DOI: 10.21873/anticanres.13565 
16 Higuchi T, Sugisawa N, Miyake K, Oshiro H, Yamamoto N, Hayashi K, Kimura H, Miwa S, Igarashi K, Kline Z, Belt P, Chawla SP, Bouvet M, Singh SR, Tsuchiya H and Hoffman RM: Combination treatment with sorafenib and everolimus regresses a doxorubicin-resistant osteosarcoma in a PDOX mouse model. Anticancer Res 39(9): 4781-4786, 2019. PMID: 31519579. DOI: 10.21873/anticanres.13662

17 Higuchi T, Sugisawa N, Miyake K, Oshiro H, Yamamoto N, Hayashi K, Kimura H, Miwa S, Igarashi K, Kline Z, Bouvet M, Singh SR, Tsuchiya H and Hoffman RM: Pioglitazone, an agonist of PPAR $\gamma$, reverses doxorubicin-resistance in an osteosarcoma patient-derived orthotopic xenograft model by downregulating Pglycoprotein expression. Biomed Pharmacother 118: 109356, 2019. PMID: 31545293. DOI: 10.1016/j.biopha.2019.109356

18 Higuchi T, Sugisawa N, Yamamoto J, Oshiro H, Han Q, Yamamoto N, Hayashi K, Kimura H, Miwa S, Igarashi K, Tan Y, Kuchipudi S, Bouvet M, Singh SR, Tsuchiya H and Hoffman RM: The combination of oral-recombinant methioninase and azacitidine arrests a chemotherapy-resistant osteosarcoma patient-derived orthotopic xenograft mouse model. Cancer Chemother Pharmacol 85(2): 285-291, 2020. PMID: 31705268. DOI: $10.1007 / \mathrm{s} 00280-019-03986-0$

19 Higuchi T, Yamamoto J, Sugisawa N, Tashiro Y, Nishino H, Yamamoto N, Hayashi K, Kimura H, Miwa S, Igarashi K, Bouvet M, Singh SR, Tsuchiya $\mathrm{H}$ and Hoffman RM: PPAR $\gamma$ agonist pioglitazone in combination with cisplatinum arrests a chemotherapy-resistant osteosarcoma PDOX model. Cancer Genomics Proteomics 17(1): 35-40, 2020. PMID: 31882549. DOI: $10.21873 / \operatorname{cgp} .20165$

20 Higuchi T, Miyake K, Oshiro H, Sugisawa N, Yamamoto N, Hayashi K, Kimura H, Miwa S, Igarashi K, Chawla SP, Bouvet M, Singh SR, Tsuchiya H and Hoffman RM: Trabectedin and irinotecan combination regresses a cisplatinum-resistant osteosarcoma in a patient-derived orthotopic xenograft nudemouse model. Biochem Biophys Res Commun 513(2): 326-331, 2019. PMID: 30955860. DOI: 10.1016/j.bbrc.2019.03.191
21 Kiyuna T, Tome Y, Miyake K, Murakami T, Oshiro H, Igarashi K, Kawaguchi K, Hsu J, Singh M, Li Y, Nelson S, Bouvet M, Singh SR, Kanaya F and Hoffman RM: Eribulin suppressed cisplatinum- and doxorubicin-resistant recurrent lung metastatic osteosarcoma in a patient-derived orthotopic xenograft mouse model. Anticancer Res 39(9): 4775-4779, 2019. PMID: 31519578. DOI: 10.21873/anticanres.13661

22 Marchetto A, Ohmura S, Orth MF, Knott MML, Colombo MV, Arrigoni C, Bardinet V, Saucier D, Wehweck FS, Li J, Stein S, Gerke JS, Baldauf MC, Musa J, Dallmayer M, Romero-Pérez L, Hölting TLB, Amatruda JF, Cossarizza A, Henssen AG, Kirchner T, Moretti M, Cidre-Aranaz F, Sannino G and Grünewald TGP: Oncogenic hijacking of a developmental transcription factor evokes vulnerability toward oxidative stress in Ewing sarcoma. Nat Commun 11(1): 2423, 2020. PMID: 32415069. DOI: 10.1038/s41467-020-16244-2

23 Kondo T: Current status and future outlook for patient-derived cancer models from a rare cancer research perspective. Cancer Sci 112(3): 953-961, 2021. PMID: 32986888. DOI: 10.1111/cas.14669

24 Igarashi K, Kawaguchi K, Li S, Han Q, Tan Y, Murakami T, Kiyuna T, Miyake K, Miyake M, Singh AS, Eckardt MA, Nelson SD, Russell TA, Dry SM, Li Y, Yamamoto N, Hayashi K, Kimura H, Miwa S, Tsuchiya H, Singh SR, Eilber FC and Hoffman RM: Recombinant methioninase in combination with doxorubicin (DOX) overcomes first-line DOX resistance in a patient-derived orthotopic xenograft nude-mouse model of undifferentiated spindle-cell sarcoma. Cancer Lett 417: 168-173, 2018. PMID: 29306021. DOI: 10.1016/j.canlet.2017.12.028

Received March 3, 2021

Revised March 12, 2021

Accepted March 16, 2021 